\title{
Plasma electrolytic oxidation and corrosion protection of friction stir welded AZ31B magnesium alloy-titanium joints
}

DOI:

10.1016/j.surfcoat.2020.125838

\section{Document Version}

Accepted author manuscript

Link to publication record in Manchester Research Explorer

\section{Citation for published version (APA):}

Aliasghari, S., Rogov, A., Skeldon, P., Zhou, X., Yerokhin, A., Aliabadi, A., \& Ghorbani, M. (2020). Plasma electrolytic oxidation and corrosion protection of friction stir welded AZ31B magnesium alloy-titanium joints. Surface and Coatings Technology, 125838. https://doi.org/10.1016/j.surfcoat.2020.125838

\section{Published in:}

Surface and Coatings Technology

\section{Citing this paper}

Please note that where the full-text provided on Manchester Research Explorer is the Author Accepted Manuscript or Proof version this may differ from the final Published version. If citing, it is advised that you check and use the publisher's definitive version.

\section{General rights}

Copyright and moral rights for the publications made accessible in the Research Explorer are retained by the authors and/or other copyright owners and it is a condition of accessing publications that users recognise and abide by the legal requirements associated with these rights.

\section{Takedown policy}

If you believe that this document breaches copyright please refer to the University of Manchester's Takedown Procedures [http://man.ac.uk/04Y6Bo] or contact uml.scholarlycommunications@manchester.ac.uk providing relevant details, so we can investigate your claim.

\section{OPEN ACCESS}




\title{
Plasma electrolytic oxidation and corrosion protection of friction stir welded AZ31B magnesium alloy-titanium joints
}

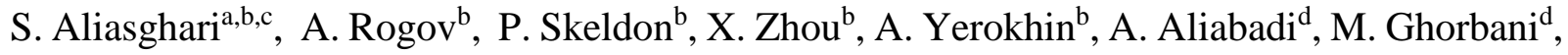 \\ a ASTeC, STFC Daresbury Laboratory, Daresbury, Warrington, Cheshire WA4 4AD, UK. \\ ${ }^{\mathrm{b}}$ Corrosion and Protection Group, Department of Materials, The University of Manchester, Oxford Rd., Manchester \\ M13 9PL, England, U.K. \\ 'Iranian Light Source Facility, ILSF, Institute for Research in Fundamental Sciences, IPM, Tehran, Iran \\ ${ }^{\mathrm{d} D e p a r t m e n t ~ o f ~ M a t e r i a l s ~ S c i e n c e ~ a n d ~ E n g i n e e r i n g, ~ S h a r i f ~ U n i v e r s i t y ~ o f ~ T e c h n o l o g y, ~ P . O . ~ B o x ~ 11365-9466 . ~ A z a d i ~}$ \\ Avenue, 14588 Tehran, Iran.
}




\begin{abstract}
Joining of dissimilar light metals by friction stir welding (FSW) is of interest to reduce weight and fuel consumption in the transport sector. Such coupled metals may need protective surface treatments, e.g. against wear or corrosion, for some applications. In this work, the formation of plasma electrolytic oxidation (PEO) coatings in a silicate-based electrolyte for corrosion protection of FSW AZ31B magnesium alloy-titanium joints has been studied. The joints, if unprotected, may be susceptible to severe galvanic corrosion in chloride-containing environments. The coatings were characterized by scanning electron microscopy, energy-dispersive spectroscopy and X-ray diffraction. $\mathrm{Mg}_{2} \mathrm{SiO}_{4}$ and $\mathrm{MgO}$ were identified in the coating on the AZ31B alloy and rutile and anatase on the titanium. Immersion of the joints in $3.5 \mathrm{wt} \%$ sodium chloride solution for $24 \mathrm{~h}$ resulted in severe corrosion of the AZ31B alloy in an uncoated joint; in contrast, corrosion of the AZ31B alloy was localized following PEO owing to the barrier protection provided by the coating. Corrosion of the titanium was negligible. The severe corrosion of the unprotected AZ31B alloy led to precipitation of a large amount of $\mathrm{Mg}(\mathrm{OH})_{2}$ from the sodium chloride solution by the end of the test. The weight of precipitate was reduced by a factor of $\approx 8$ by the application of the PEO coating.
\end{abstract}

Keywords: plasma electrolytic oxidation, magnesium, titanium, friction stir welding, corrosion resistance

\title{
1. Introduction
}

Design improvements for enhanced performance and reduced environmental impact, for instance in automobile manufacture, often requires joining of different metals that offer specific desirable properties. A wide range of joining process are available, for example, fasteners, conventional welding, friction stir welding and laser welding [1-8]. In applications where corrosion or wear might occur, a surface treatment can be applied to minimize any potential degradation of the joint. A single-step treatment able to satisfactorily protect both metal parts of a joint would be a practical advantage. In the case of joints comprising light metals (aluminium, magnesium and titanium) and 
their alloys, which are often selected when weight reduction is a design priority, anodizing [9-13] and plasma electrolytic oxidation (PEO) [14-18] are potential options, since all three types of metal can be treated by these methods. However, anodizing requires an electrolyte compatible with both components of the joint, which can be difficult to achieve, and the resultant oxide coatings may be too thin to be useful. On the other hand, environmentally-compliant electrolytes are available that are potentially suited to PEO of various combinations of mixed light metals. The resultant ceramic coatings can be tens of microns thick and provide thermal [19], corrosion [20] and wear [21, 22] resistance. The coatings may also be post-treated, e.g by sol-gel-treatment [23] or painting [24], or infiltrated by an inhibitor [25], to provide additional corrosion protection.

PEO coatings are formed at high voltages under DC, AC or pulsed DC electrical regimes that generate microdischarges on the substrate with $\mu \mathrm{s}$ to $\mathrm{ms}$ lifetimes [26, 27]. The coating composition and morphology depend upon the electrolyte composition, treatment time and electrical parameters (e.g. current density, voltage and waveform) [14-18]. Although there are many papers available on coating growth and properties, few relate to treatment of joined metals. A study of Al/AA7075 Al alloy and AA7075 Al alloy/ ZE41 Mg joints demonstrated that coating

thickness was determined by the charge passed through each substrate [28]. Other work revealed an increased coating thickness at the join line on an aluminium alloy clad-AZ31 magnesium core alloy [29].

The present work investigated PEO of friction stir welded AZ31B magnesium alloy-titanium joints and the corrosion protection of the PEO-treated joint. The couple, which has not been investigated before, combines poorly (AZ31B alloy) and highly (titanium) corrosion resistant substrates. If unprotected the joint would be expected to undergo galvanic corrosion of the magnesium in saline environments.

\section{Experimental}

Butt joints of $50 \times 150 \times 2 \mathrm{~mm}$ rectangular sheets of commercial purity (99.6\%) titanium and AZ31B magnesium alloy (Al 2.5-3.5\%, Zn 0.7-1.3\%, Mn 0.2-1.0\%, Mg bal.) were prepared by FSW. FSW was selected for joining as the divergent properties of the substrates, e.g. melting point 
(Ti: $1668{ }^{\circ} \mathrm{C}, \mathrm{Mg}: 650^{\circ} \mathrm{C}$ ), thermal conductivity $\left(\mathrm{Mg}: 156 \mathrm{~W} \mathrm{~m}^{-1} \mathrm{~K}^{-1}\right.$, Ti:21.9 $\left.\mathrm{W} \mathrm{m}^{-1} \mathrm{k}^{-1}\right)$, and low mutual solubility restrict conventional welding [30]. The root surface of each sheet was machined, rinsed and degreased with acetone before joining. A tool of $20 \mathrm{~mm}$ diameter was applied (AISI Type H13 hotwork tool steel) with a shoulder diameter of $16 \mathrm{~mm}$, probe length of $2.7 \mathrm{~mm}$ and probe diameter of $4.0 \mathrm{~mm}$. The screw-type probe was inserted in the magnesium side and the probe edge was slightly offset into the titanium sheet, separated by 0.5 or $1.5 \mathrm{~mm}$ from the joint interface (Fig. 1). The harder titanium was set at the advancing side to make a clean interface surface by abrading it with the probe edge. The FSW parameters were as follows: rotation speed $900 \mathrm{rpm}$, loading force $7.5 \mathrm{kN}$, tool tilt $3^{\circ}$, forward travel speed $50 \mathrm{~mm} \mathrm{~min}^{-1}$ and weld length $125 \mathrm{~mm}$.

Following FSW, specimens of size 150 x $10 \mathrm{~mm}$ were cut from a weld for treatment by PEO. They were first ground to a 2500 grit $\mathrm{SiC}$ finish and ultrasonically degreased in acetone for 15 min, rinsed with deionised water and dried in a stream of warm air. Specimens were also prepared of the AZ31B and titanium parent materials. PEO was carried out using an Advanced Energy MDX-II DC power supply. The electrolyte was prepared by dissolving $10 \mathrm{~g}^{-1} \mathrm{Na}_{2} \mathrm{SiO}_{3}$, $2 \mathrm{~g} \mathrm{l}^{-1} \mathrm{NaF}, 2 \mathrm{~g} \mathrm{~L}^{-1}$ and $3 \mathrm{~g} \mathrm{l}^{-1} \mathrm{KOH}$ (ACS grades) in deionised water. The electrolyte of volume $0.6 \mathrm{dm}^{-3}$ was contained in a glass cell and stirred with a magnetic stirrer during PEO. The temperature of the electrolyte was maintained within the range of 10 to $35^{\circ} \mathrm{C}$. The working area of the specimens was approximately $10 \mathrm{~cm}^{2}$. The weld specimen had equal areas of AZ31B alloy and titanium exposed to the electrolyte. A stainless steel (304) plate of dimensions 12 x $5 \mathrm{~cm}$ was used as the cathode. The working regime comprised $1 \mathrm{~min}$ of voltage ramp from 0 to $500 \mathrm{~V}$ followed by $10 \mathrm{~min}$ at a constant current density of $200 \mathrm{~mA} \mathrm{~cm}^{-2}$. Preliminary work of some of the present authors indicated that PEO coatings could be produced on the individual AZ31B alloy and titanium substrates under the present PEO conditions [31]. The study investigated a range of silicate concentrations, with $10 \mathrm{~g} \mathrm{l}^{-1}$ being preferred for optimum corrosion resistance. Data were recorded every second with a National Instrument dual channel digitiser NI-PXI-5922 in conjunction with in-house Labview software. . The current-voltage and voltage-time curves were measured five times with good reproducibility. On completion of PEO, the specimens were rinsed in running water and dried in ambient air. 
Plan and cross-section views of PEO-treated specimens were observed using a Tescan MIRAJ field emission scanning electron microscope equipped with energy-dispersive spectroscopy (EDS) facilities. Cross-sections were wet-ground, using ethanol, through successive grades of $\mathrm{SiC}$ paper and finished with $1 \mu \mathrm{m}$ diamond paste. Coatings were also investigated by X-ray diffraction (XRD), using a Philips X'Pert Pro MPD (PANanalytical) instrument with copper K $\alpha$ radiation, a step size of $0.02^{\circ}$ per min and a scan range from $5^{\circ}$ to $85^{\circ}$ (in 20). Measurements were made on a $1 \mathrm{x} 1 \mathrm{~cm}$ area of PEO-treated weld with the join line located centrally. Phases were identified using the X'Pert database.

The corrosion behaviour of bare and coated FSW AZ31B alloy-titanium joints was compared following immersion for $24 \mathrm{~h}$ in naturally-aerated $3.5 \mathrm{wt}$.\% sodium chloride solution at room temperature. The individual specimens were placed in separate glass beakers containing $200 \mathrm{~cm}^{3}$ of quiescent sodium chloride solution. The specimens were held vertically in the solution. On removal from the solution, the specimens were rinsed in deionised water and dried. The solid corrosion products deposited in each beaker were collected by filtration, dried in an oven at 110 ${ }^{\circ} \mathrm{C}$ for $24 \mathrm{~h}$, then weighed.

\section{Results and discussion}

\subsection{Electrochemical response during coating formation}

Figure 2 (a) illustrates the current density during first stage of the PEO process, which involved a voltage scan from $0 \mathrm{~V}$ to $500 \mathrm{~V}$ in $1 \mathrm{~min}\left(8.33 \mathrm{~V} \mathrm{~s}^{-1}\right)$. Results are shown for the FSW AZ31B alloytitanium joint and also for the parent titanium and AZ31B alloy. Scanning the voltage at a constant rate is expected to first result in growth of a barrier type anodic film on both titanium and AZ31 B alloy, with the film thickness proportional to the voltage. In the absence of side reactions, the current density is determined by high-field ionic transport through the barrier film [32]. Previous work on anodizing titanium showed that a voltage ramp at about $1.4 \mathrm{~V} \mathrm{~s}^{-1}$ is associated with a current density of $5 \mathrm{~mA} \mathrm{~cm}^{-2}$ [32]. Hence, under the present voltage ramp, the growth of a barrier film at a constant current density of $\approx 30 \mathrm{~mA} \mathrm{~cm}^{-2}$ would be expected, which is reasonably similar to the measured value of $\approx 25 \mathrm{~mA} \mathrm{~cm}$. At voltages above about $20 \mathrm{~V}$, oxygen evolution 
increasingly accompanies the film growth $[32,33]$, which explains the gradually rising current density. With onset of dielectric breakdown, at $\approx 320 \mathrm{~V}$, the current density increases more steeply and is dependent on the population density and intensity of sparks at a particular voltage. In the case of the AZ31B alloy, localized anodic dissolution followed by passivation, leading to a current peak (see arrow A), occurs in parallel with the initial barrier film growth. Oxygen evolution is less significant compared with the titanium, until dielectric breakdown begins at $\approx 420 \mathrm{~V}$. The peak due to anodic dissolution was lower for the weld than for the AZ31B alloy specimen due to the reduced alloy area. Sparking first commenced on the titanium and later on the AZ31B alloy causing the current density to reduce below that of the individual titanium specimen (see arrow B).

Figure 2 (b) shows the voltage-time relationship during the second stage of PEO under a constant current density of $200 \mathrm{~mA} \mathrm{~cm}{ }^{-2}$ The AZ31B alloy exhibited a continuously rising voltage from 490 to $535 \mathrm{~V}$. In contrast, the lower voltages were recorded for the titanium and AZ31B alloytitanium joint: 458-463 V and 465-470 V, respectively. The initial decrease in voltage was possibly associated with the increase in electrolyte temperature (Fig. 2 (b)). In this stage, microdischarges were present on both the AZ31B alloy and titanium parts of the joint. The coating material may form due to a combination of anodic oxidation, thermal oxidation, and plasma-chemical reactions, under the high temperatures and pressures associated with the microdischarges. The current-voltage behaviours for the AZ31B alloy and titanium (Fig. 2 (a)) suggest that the current density, and hence the coating thickness, should be lower on the alloy part of the joint than on the titanium part following the second stage of the treatment. However, the difference in current density cannot be quantified from Fig. 2 (a) owing to the different electrical regimes and the evolution of the microdischarges (number, type and intensity) with time.

\subsection{Coating morphology and composition}

Figures 3 (a) and (b) show secondary electron micrographs at different magnifications of the surface of a PEO-coated FSW AZ31B alloy-titanium joint. The regions on the left-hand and righthand halves of the micrographs correspond to the coatings above the AZ31B alloy and titanium parts of the joint, respectively. No interfacial region of intermediate morphology was 
distinguishable, which is consistent with a sharp compositional boundary between the AZ31B alloy and titanium disclosed in the later cross-sectional images. The coating on the titanium has a much coarser appearance than the coating on the AZ31B alloy and exhibits a wide range of pore diameters, from several tens of microns to sub-micron. In contrast, the pores in the coating on the AZ31B alloy are generally finer and the agglomerations of nodular deposits that decorate large areas of the surface of the coating on the titanium are absent. EDS (Table 1) showed that the coatings on both substrates contained high concentrations of oxygen and silicon and lower concentrations of sodium, potassium and fluorine in addition to the substrate elements. The porosity in the coatings was formed by the escape from the softened and melted coating of gas (hydrogen, oxygen and water vapour) that is copiously evolved during the coating growth $[34,35]$.

XRD measurements on the AZ31B alloy-titanium joint disclosed peaks for $\mathrm{MgO}, \mathrm{Mg}_{2} \mathrm{SiO}_{4}$ in the coating on the $\mathrm{AZ31B}$ alloy and $\mathrm{TiO}_{2}$ (rutile and anatase) in the coating on titanium, and also peaks from the two substrates (Fig. 4). The coating constituents are commonly found in PEO coatings on magnesium $[22,36,37]$ and titanium $[17,38] . \mathrm{Mg}_{2} \mathrm{TiO}_{4}$ might have been formed in the join region, which produces peaks that overlap with ones of $\mathrm{MgO}$ and $\mathrm{Mg}_{2} \mathrm{SiO}_{4}$.

The coating constituents are formed by reaction between $\mathrm{Mg}^{2+}$ and $\mathrm{Ti}^{4+}$ ions generated by oxidation of the respective substrates and either water molecules or the constituent anions ions of the electrolyte, the latter being transported towards the microdischarges by the electric filed across the coating. The absence of peaks for crystalline titanium-silicon phases is probably due to the presence of silicon as amorphous silica (as found previously for coatings on titanium [17, 22]) which can form by thermolysis of $\mathrm{SiO}_{3}{ }^{2-}$ ions.

Figures 5 (a) and (b) present backscattered electron micrographs at different magnifications of a cross-section of a PEO-treated FSW AZ31B alloy-titanium joint. The titanium side of the joint appears lighter due to the greater electron scattering from titanium than from the AZ31B alloy. The weld interface is irregular due to the severe deformation caused by the offset screw-type probe. According to EDS point analysis, the darker patches (shown by an arrow) in the AZ31B alloy contain a high concentration of oxygen, and are possibly corrosion products formed during preparation of the cross-section. PEO has produced a porous coating between 4-12 $\mu \mathrm{m}$ thick on 
the AZ31B alloy and 5-18 $\mu \mathrm{m}$ thick on the titanium, with respective average thicknesses of $\approx 6$ and $10 \mu \mathrm{m}$. The variability of the coating thickness on the individual substrates, which typical of DC PEO coatings, is due to the localization of coating growth at discharge sites. The greater thickness of the coating on titanium is consistent with current flowing preferentially to the titanium side of the joint, as would be expected from the current-density-voltage and voltage-time curves of Fig. 2. However, the coating thicknesses are also affected by the porosities, densities and compositions of the respective coatings and losses of coating species to the electrolyte. For example, the Pilling-Bedworth ratios (volume of oxide formed per metal ion:volume of metal per metal atom for non-porous $\mathrm{MgO}, \mathrm{Mg}_{2} \mathrm{SiO}_{4}, \mathrm{TiO}_{2}$ (anatase) and $\mathrm{TiO}_{2}$ (rutile) are $\approx 0.81,1.55,1.99$ and 1.78 , respectively.

Semi-quantitative EDS analysis of the concentration of titanium, magnesium, aluminium and zinc across the join line (Figs. 5 (c) and (d)) show negligible inter-mixing of the constituent elements of the two parts of the weld. The steep changes in the concentrations of magnesium and titanium across the join are due to the low mutual solubility of the two elements and the absence of interfacial intermetallic phases [30]. In Fig. 5 (c) only, the aluminium concentration increased near the interface (within $\approx 1 \mu \mathrm{m}$ of the interface) may be a result of either diffusion of aluminium to the interface during FSW, where it may form $\mathrm{Mg}_{17} \mathrm{Al}_{12}$ or $\mathrm{TiAl}_{3}$ [30], or the presence of an $\mathrm{Al}-\mathrm{Mn}$ intermetallic particle of the AZ31B alloy [39]. The titanium peak in the region of the AZ31B alloy in Fig. 5 (d) may be due to a fragment scoured from the titanium surface by the probe and subsequently transported into the melted AZ31B alloy.

An EDS line scan in the coating across the join line shows that the concentration of magnesium in the coating decreased over a distance of about $3 \mu \mathrm{m}$ to negligible levels at the joint interface (Fig. $6(\mathrm{a}-\mathrm{c}))$. At this point, the concentration of titanium increased. The aluminium signal revealed a peak at the interface (Fig. 6 (d)), which might have arisen from formation of $\mathrm{Mg}_{17} \mathrm{Al}_{12}$ phase. This phase has been reported in previous work to form at the interface in FSW and laser-welded AZ31titanium joints [30, 40]. However, the line intensities fluctuate significantly owing to the variable porosity, the composition of the coating above both substrates and variable distance of the line from the substrates. The line scans from other coating constituents, such as oxygen, silicon and fluorine, are not shown since the X-ray intensities revealed no significant trend across the weld. 


\subsection{Corrosion behaviour}

The photographs in Fig. 7 show the appearance of two specimens respectively in the bare and PEO treated condition following immersion for $24 \mathrm{~h}$ in the $3.5 \mathrm{wt} \%$ sodium chloride solution. In the absence of the coating, the whole of the exposed area of AZ31B alloy was severely corroded. Corrosion of the titanium was comparatively negligible. In contrast, corrosion of the coated specimen was limited to a few sites that appear dark in the photograph (see arrows) where the coating had been lost and attack of the substrate was evident. Similar localized corrosion was present on the opposite side of the specimen. Most of the coated surfaces had been protected by the coating. The coated titanium surface was negligibly affected by the exposure to the solution.

The large difference in the amount of corrosion on the two specimens was confirmed by the amount of precipitate in the beaker at the end of the test period, shown in the photographs of Fig. 8. The solution that contained the uncoated specimen was of grey colour and a thick layer of $\mathrm{Mg}(\mathrm{OH})_{2}$, had deposited on the base of the beaker. In marked contrast, the solution that contained the coated specimen was clear and only a small amount of $\mathrm{Mg}(\mathrm{OH})_{2}$ had deposited in the beaker. The weights of the precipitate for the uncoated and coated specimens were $2.75 \mathrm{~g}$ (equivalent to $\approx 100 \mu \mathrm{m}$ loss from each surface of the AZ31B alloy) and $0.34 \mathrm{~g}$, respectively. Hence, the amount of $\mathrm{Mg}(\mathrm{OH})_{2}$ was reduced by a factor of 8 by the PEO treatment. However, this may underestimate the reduction of corrosion, since it neglects consideration of $\mathrm{Mg}^{2+}$ ions dissolved and in the sodium chloride solution and of solid corrosion products attached to the specimen surface. Furthermore, the greater amount of $\mathrm{Mg}(\mathrm{OH})_{2}$ formed from the bare alloy would have caused a more rapid rise in $\mathrm{pH}$ of the sodium chloride solution, which would have slowed the corrosion compared with the coated alloy. The $3.5 \mathrm{wt} . \%$ sodium chloride solution provides a severe test of the corrosion protection by the PEO coating and greater benefits of the PEO treatment would be expected in less concentrated environments.

PEO coatings usually provide only barrier protection, which is largely dependent on the integrity of the barrier layer of oxide, $\lesssim 1 \mu \mathrm{m}$ thick, at the base of the coating [36,41]. The porous outer region may also assist the corrosion protection by slowing transport of species between the substrate and the bulk solution. If the barrier layer integrity in a coating on magnesium is impaired, 
due to the inevitable presence of defects, the solution can gain access to the metal and initiate corrosion. Additional to the barrier protection of the AZ31B alloy, the PEO coating on the weld can block access of the solution to the titanium surface and hence, reduce the galvanic influence of the titanium on corrosion of the coated alloy. The findings show the potential benefits of PEO to protection of a mixed light metal joint potentially susceptible to severe galvanic corrosion. A further level of protection of the joint could be provided by application of a sol-gel or organic coating that can block the pores and limit access of solution to the substrates.

\section{Conclusions}

1. A PEO coating can be formed on FSW AZ31B alloy-titanium in a silicate-based solution that can significantly reduce the severe corrosion of the AZ31B alloy that occurs when no coating is present. The coating above the $\mathrm{AZ31B}$ alloy contained $\mathrm{MgSiO}_{3}$ and $\mathrm{MgO}$; rutile and anatase were present above the titanium. Owing to preferential flow of current to the titanium part of the joint and to differences in the composition and porosity of the coatings, a thinner coating was formed above the AZ31B alloy $(\approx 6 \mu \mathrm{m})$ than above the titanium $(\approx 10 \mu \mathrm{m})$.

2. Severe corrosion occurred for the AZ31B part of the bare joint after $24 \mathrm{~h}$ immersion in $3.5 \mathrm{wt} . \%$ sodium chloride solution. PEO significantly reduced the corrosion owing to barrier protection of the AZ31B alloy and the titanium.

\section{Acknowledgements}

The authors acknowledge funding from the European Union's Horizon 2020 research and innovation programme under the Marie Skłodowska-Curie grant agreement No. 665593 awarded to UKRI Science and Technology Facilities Council (STFC).

\section{Data availability}

The raw/processed data required to reproduce these findings cannot be shared at this time as the data also forms part of an ongoing study. 


\section{References}

[1] L. Fratini, F. Micari, A. Squillace, G. Gioleo, Experimental characterization of FSW T-joints of light alloys, Key Eng. Mater. 344 (2007) 751-758.

[2] M. Gao, C. Chen, Y,. Gu, X. Zeng, Microstructure and tensile behavior of laser arc hybrid welded dissimilar Al and Ti alloys, Materials 7 (2014) 1590-1602.

[3] Liming Liu, Daxin Ren, Fei Liu, A review of dissimilar welding techniques for magnesium alloys to aluminum alloys, Materials 7 (2014) 3735-3757.

[4] M. Sahul, M. Turňa, M. Sahul, Welding of dissimilar light metals by disk laser, In: Alderman M., Manuel M.V., Hort N., Neelameggham N.R. (eds) Magnesium Technology 2014. Springer, Cham.

[5] M. Aonuma., K.Nakata. Dissimilar metal joining of ZK60 magnesium alloy and titanium by friction stir welding, Mater. Sci. Eng. B (2012) 543-548.

[6] M.R. Islam, M. Ishak, L.H. Shah, S.R.A. Idris, C. Meriç, Dissimilar welding of A7075-T651 and AZ31B alloys by gas metal arc plug welding method, Int. J. Adv. Manuf. Technol. 88 (2017) 2773-2783.

[7] G. Çam, G. Ipekoğlu, Recent developments in joining of aluminum alloys, Int. J. Adv.Manuf. Technol., 91 (2017) 1851-1866.

[8] Y.M. Baqer, S. Ramesh, F. Yusof, S.M. Manladan, Challenges and advances in laser welding of dissimilar light alloys: Al/Mg, Al/Ti, and Mg/Ti alloys, Int. J. Adv. Manuf. Technol. 95 (2018) 4353-4369.

[9] P. G. Sheasby, R. Pinner, The Surface Treatment and Finishing of Aluminium and Its Alloys, ASM International; 6th Edition (2001).

[10] Y. Huang, H. Shih, H. Huang, J. Daugherty, S. Wu, S. Ramanathan, C. Chang, F. Mansfeld, Evaluation of the corrosion resistance of anodized aluminum 6061 using electrochemical impedance spectroscopy (EIS), Corros. Sci. 50 (2008) 3569-3575.

[11] C. Blawert, W. Dietzel, E. Ghali, G. Song, Anodizing treatments for magnesium alloys and their effect on corrosion resistance in various environments, Adv. Eng. Mater. 8 (2006) 511-533. 
[12] S.A. Salman, M. Okido, Anodization of magnesium (Mg) alloys to improve corrosion resistance, Chptr. 8 in Corrosion Prevention of Magnesium Alloys, Woodhead Publishing Series in Metals and Surface Engineering (2013), Pages 197-231.

[13] D. Prando, A. Brenna, M.V. Diamanti, S. Beretta, F. Bolzoni, M. Ormellese, M. Pedeferri, Corrosion of titanium: Part 2: Effects of surface treatments, J. Appl. Biomater. Func. Mater. 16 (2017) 3-13.

[14] A.L. Yerokhin, X. Nie, A. Leyland, A. Matthews, S.J. Dowey, Plasma electrolysis for surface engineering, Surf. Coat. Technol. 122 (1999) 73-93.

[15] Xiaopeng Lu, Marta Mohedano, Carsten Blawert, Endzhe Matykina, Raul Arrabal, Karl Ulrich Kainer, Mikhail L. Zheludkevich, Plasma electrolytic oxidation coatings with particle additions- A Review, Surf. Coat. Technol. 307 (2016) 1165-1182.

[16] Gh.B. Darband, M. Aliofkhazraei, P. Hamghalam, N.Valizade, Plasma electrolytic oxidation of magnesium and its alloys: Mechanism, properties and applications J. Magnes. Alloys 5 (2017) 74-132.

[17] A.L. Yerokhin, X. Nie, A. Leyland, A. Matthews, Characterisation of oxide films produced by plasma electrolytic oxidation of a Ti-6Al-4V alloy, Surf. Coat. Technol. 130 (2000) 195-206. [18] F.C. Walsh, C.T.J. Low, R.J.K. Wood, K.T. Stevens, J. Archer, A.R. Poeton, A. Ryder, Plasma electrolytic oxidation (PEO) for production of anodised coatings on lightweight metal (Al, Mg, Ti) alloys, Trans. Inst. Met. Finish. 87 (2009) 122-135.

[19] J.A. Curran, H. Kalkanc1, Y. Magurova, T.W. Clyne, 2007. Mullite-rich plasma electrolytic oxide coatings for thermal barrier applications, Surf. Coat. Technol. 201 (2007) 8683-8687.

[20] M. Shokouhfar, C. Dehghanian, M. Montazeri, A. Baradaran, Preparation of ceramic coating on Ti substrate by plasma electrolytic oxidation in different electrolytes and evaluation of its corrosion resistance: Part II, Appl. Surf. Sci. 258 (2012) 2416-2423.

[21] C. Martini, L. Ceschini, F. Tarterini, J.M. Paillard, J. A. Curran, PEO layers obtained from mixed aluminate-phosphate baths on Ti-6Al-4V: Dry sliding behaviour and influence of a PTFE topcoat, Wear 26 (2010) 747-756.

[22] S. Aliasghari, P. Skeldon, G. E. Thompson, "Plasma electrolytic oxidation of titanium in a phosphate/silicate electrolyte and tribological performance of the coatings, Appl. Surf. Sci. 316 (2014) 463-476. 
[23] Z. Li, X. Jing, Y.Yuan, M. Zhang, Composite coatings on a $\mathrm{Mg}-\mathrm{Li}$ alloy prepared by combined plasma electrolytic oxidation and sol-gel techniques, Corros. Sci. 63 (2012) 358-366.

[24] R. Arrabal, J.M. Mota, A. Criado, A. Pardo, M. Mohedano, E. Matykina, Assessment of duplex coating combining plasma electrolytic oxidation and polymer layer on AZ31 magnesium alloy, Surf. Coat. Technol. 206 (2012) 4692-4703

[25] A.S. Gnedenkov, S.L. Sinebryukhov, D.V. Mashtalyar, S.V. Gnedenkov, Protective properties of inhibitor-containing composite coatings on a Mg alloy, Corros. Sci. 102 (2016) 348354.

[26] C.S. Dunleavy, I.O. Golosnoy, J.A. Curran, T.W. Clyne, Characterisation of discharge events during plasma electrolytic oxidation, Surf. Coat. Technol. 203 (2009) 3410-3419.

[27] C.S. Dunleavy, J.A. Curran, T.W. Clyne. Time dependent statistics of plasma discharge parameters during bulk AC plasma electrolytic oxidation of aluminium, Appl. Surf. Sci. 268 (2013) 397-409.

[28] A. Baron-Wiecheć, M. Curioni, R. Arrabal, E. Matykina, P. Skeldon, G. E. Thompson, Plasma electrolytic oxidation of coupled light metals, Trans. Inst. Met. Finish. 91 (2013) 107-112.

[29] G. Alisch, D. Nickel, T. Lampke, Simultaneous plasma-electrolytic anodic oxidation (PAO) of Al-Mg compounds, Surf. Coat. Tech. 206 (2011) 1085-1090.

[30] A.K. Lakshminarayanan, R. Saranarayanan, V. Karthik Srinivas, B. Venkatraman, Characteristics of friction welded AZ31B magnesium-commercial pure titanium dissimilar joints, J. Magnes. Alloys 3 (2015) 315-321.

[31] A. Aliabadi, M. Ghorbani, Gh Barati Darband, Plasma electrolytic oxidation of Mg-Ti couple metals fabricated by friction stir welding: characterization and corrosion studies, Mater. Res. Express 6 (2019) 086596.

[32] H. Habazaki, M. Uozumi, H. Konno, K. Shimizu, P. Skeldon, G.E. Thompson, Crystallization of anodic titania on titanium and its alloys, Corros. Sci. 45 (2003) 2063-2073.

[33] H. Habazaki, M. Uozumi, H. Konno, S. Nagata, K. Shimizu, Formation of barrier-type amorphous anodic films on Ti-Mo alloys, Surf. Coat. Technol. 169-170 (2003) 151-154.

[34] L.O. Snizhko, A.L. Yerokhin, N.L. Gurevina, V.A. Patalakha, A. Matthews, Excessive oxygen evolution during plasma electrolytic oxidation of aluminium, Thin Solid Films 56 (2007) 460-464. 
[35] T.W. Clyne, S.C. Troughton, A review of recent work on discharge characteristics during plasma electrolytic oxidation of various metals, Internat. Mater. Rev. 64 (2019) 127-162.

[36] R. Arrabal, E. Matykina, T. Hashimoto, P. Skeldon, G. E. Thompson, Characterization of AC PEO coatings on magnesium alloys, Surf. Coat. Technol. 203 (2009) 2207-2220.

[37] T. Chen, W. Xue, Y. Li, X. Liu, J. Du, Corrosion behavior of friction stir welded AZ31B magnesium alloy with plasma electrolytic oxidation coating formed in silicate electrolyte, Mater. Chem. Phys. 144 (2014) 462-469.

[38] K.R. Shin, Y.G. Ko, D.H. Shin, Effect of electrolyte on surface properties of pure titanium coated by plasma electrolytic oxidation, J. Alloys Compd. 509 (2011) S478-S481.

[39] C.P. Liu, F.S. Pan, W.Q. Wang, Phase analysis of Al-Mn compounds in the AZ magnesium alloys, Mater. Sci. Forum 546 (2007) 395-398.

[40] M. Gao, Z.M. Wang, X.Y. Li, X.Y. Zeng, Laser keyhole welding of dissimilar Ti-6Al-4V titanium alloy to AZ31B magnesium alloy, Metal. Mater. Trans. A 43A (2012) 163-172.

[41] E. Matykina, R. Arrabal, P. Skeldon, G.E. Thompson, Transmission electron microscopy of coatings formed by plasma electrolytic oxidation of titanium, Acta Biomater. 5 (2009) 1356-66. 


\section{Figure captions}

Figure 1. Schematic diagram of the joining FSW process of titanium and AZ31B magnesium alloy.

Figure 2. (a) Current response during a linear voltage ramp (1 min, 0-500 V) in an alkaline silicatebased electrolyte for commercial purity titanium (Ti), AZ31B alloy (Mg) and an FSW AZ31B alloy-titanium joint. (b) Voltage and temperature of the electrolyte (t) during galvanostatic PEO at $200 \mathrm{~mA} \mathrm{~cm}^{-2}$ for $10 \mathrm{~min}$.

Figure 3. (a) Scanning electron micrograph (secondary electrons) of the surface of an FSW AZ31B alloy-titanium joint following DC PEO at $200 \mathrm{~mA} \mathrm{~cm}$ for $10 \mathrm{~min}$ in an alkaline silicatebased electrolyte. (b) At increased magnification.

Figure 4. XRD patterns of an FSW AZ31B alloy-titanium joint following DC PEO at $200 \mathrm{~mA} \mathrm{~cm}^{-}$ ${ }^{2}$ for $10 \mathrm{~min}$ in an alkaline silicate-based electrolyte.

Figure 5. (a) Scanning electron micrographs (backscattered electrons) of a cross-section of an FSW AZ31B alloy-titanium joint following DC PEO at $200 \mathrm{~mA} \mathrm{~cm}^{-2}$ for $10 \mathrm{~min}$ in an alkaline silicatebased electrolyte. (b) At increased magnification. (c) and (d) EDS analysis across the join line at two different regions for magnesium, aluminium, zinc and titanium.

Figure 6. (a) Scanning electron micrograph of the join region and EDS analysis in the coating across the join line for (b) magnesium, (c) titanium and (d) aluminium.

Figure 7. Photographs of corrosion-tested FSW AZ31B alloy-titanium joints in the (a) bare condition and (b) following DC PEO at $200 \mathrm{~mA} \mathrm{~cm}^{-2}$ for $10 \mathrm{~min}$ in an alkaline silicate-based electrolyte. The joints were immersed for $24 \mathrm{~h}$ in naturally aerated $3.5 \mathrm{wt} \%$ sodium chloride solution at room temperature $\left(\approx 20^{\circ} \mathrm{C}\right)$. 
Figure 8. Photographs of the $3.5 \mathrm{wt} . \%$ sodium chloride solutions following $24 \mathrm{~h}$ immersion of (a) bare and (b) PEO-coated FSW AZ31B alloy-titanium joints. The regions above the dotted line were not exposed to the solution. 


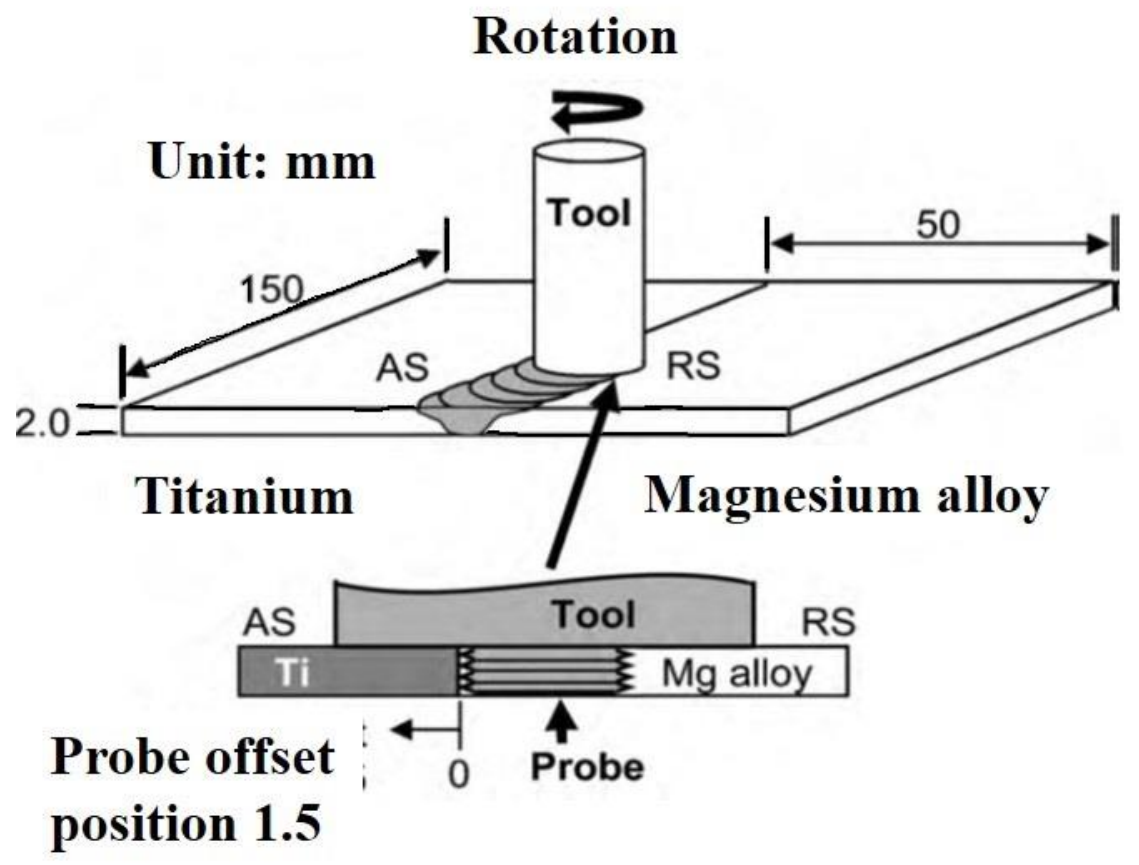

Fig 1 


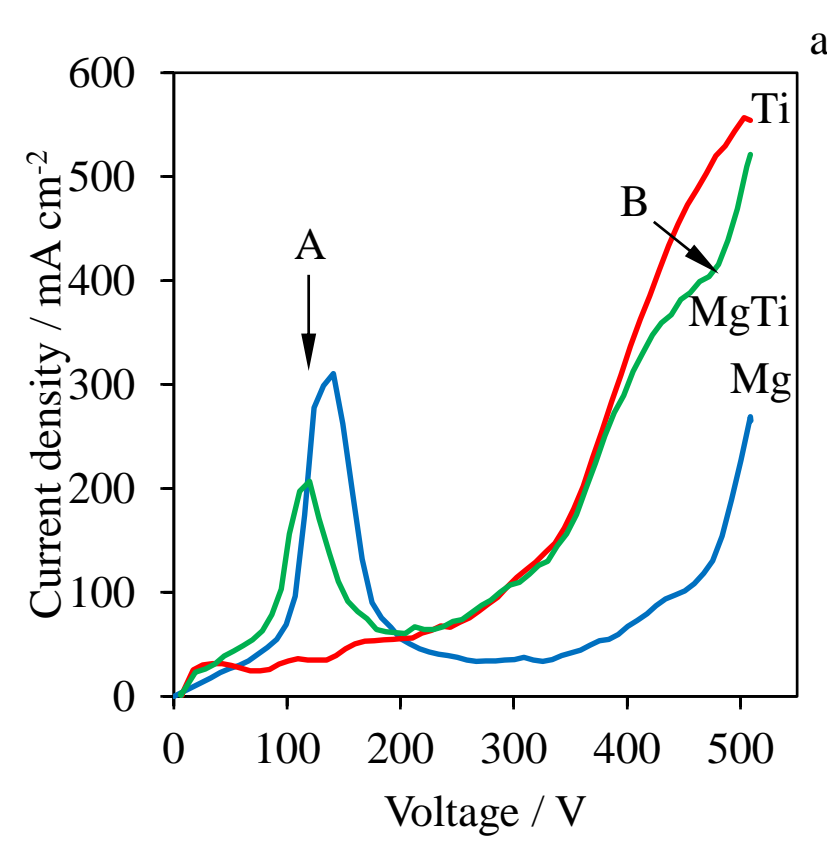

a)

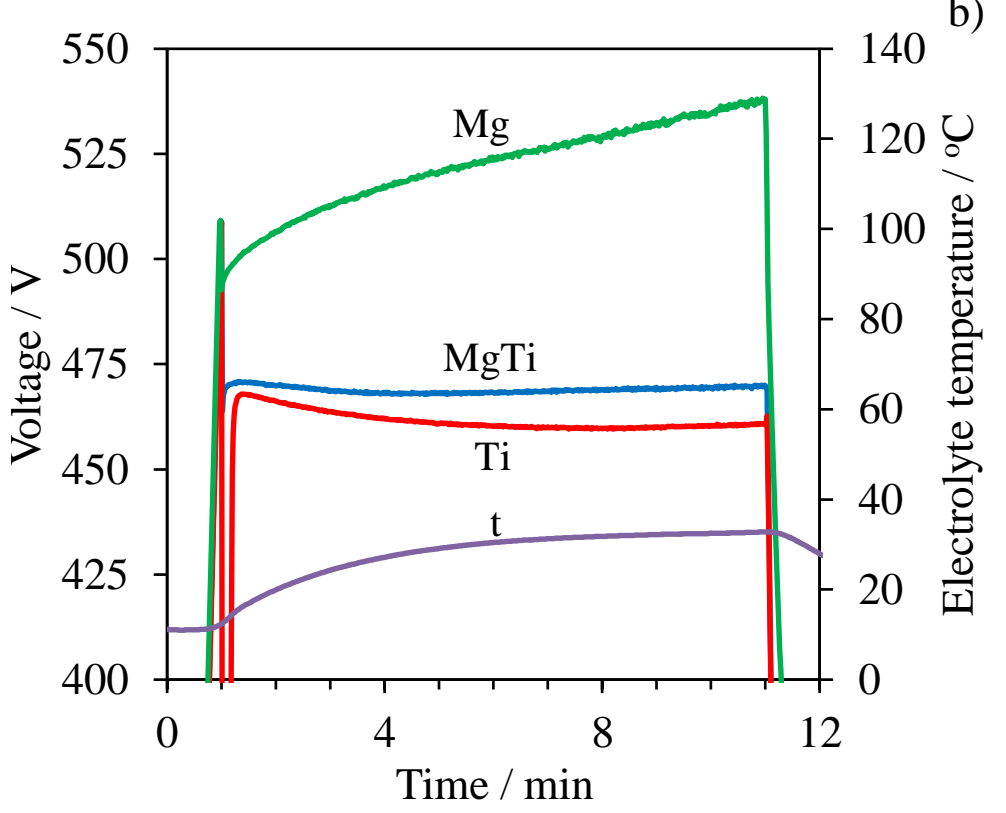

Fig 2 

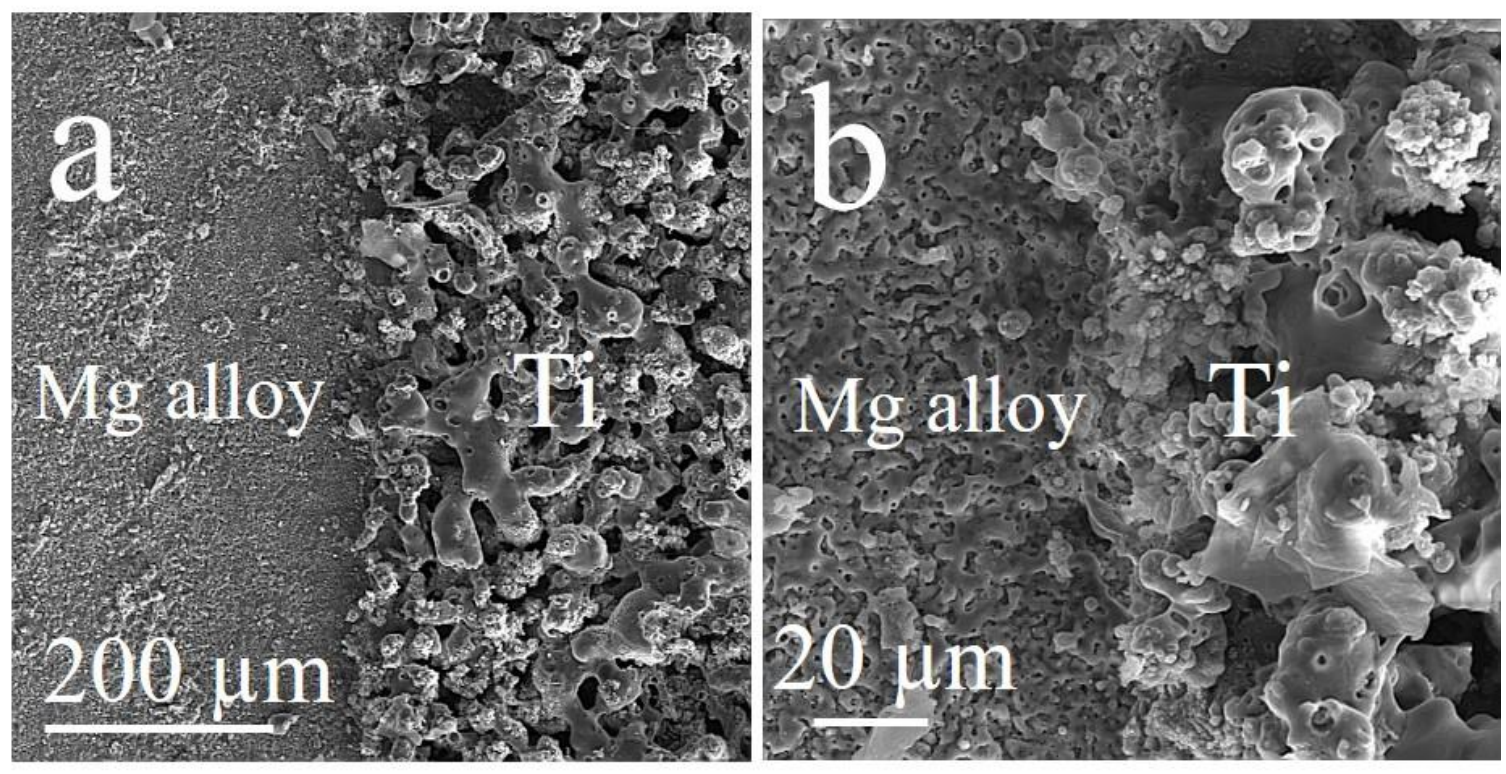

Fig 3 


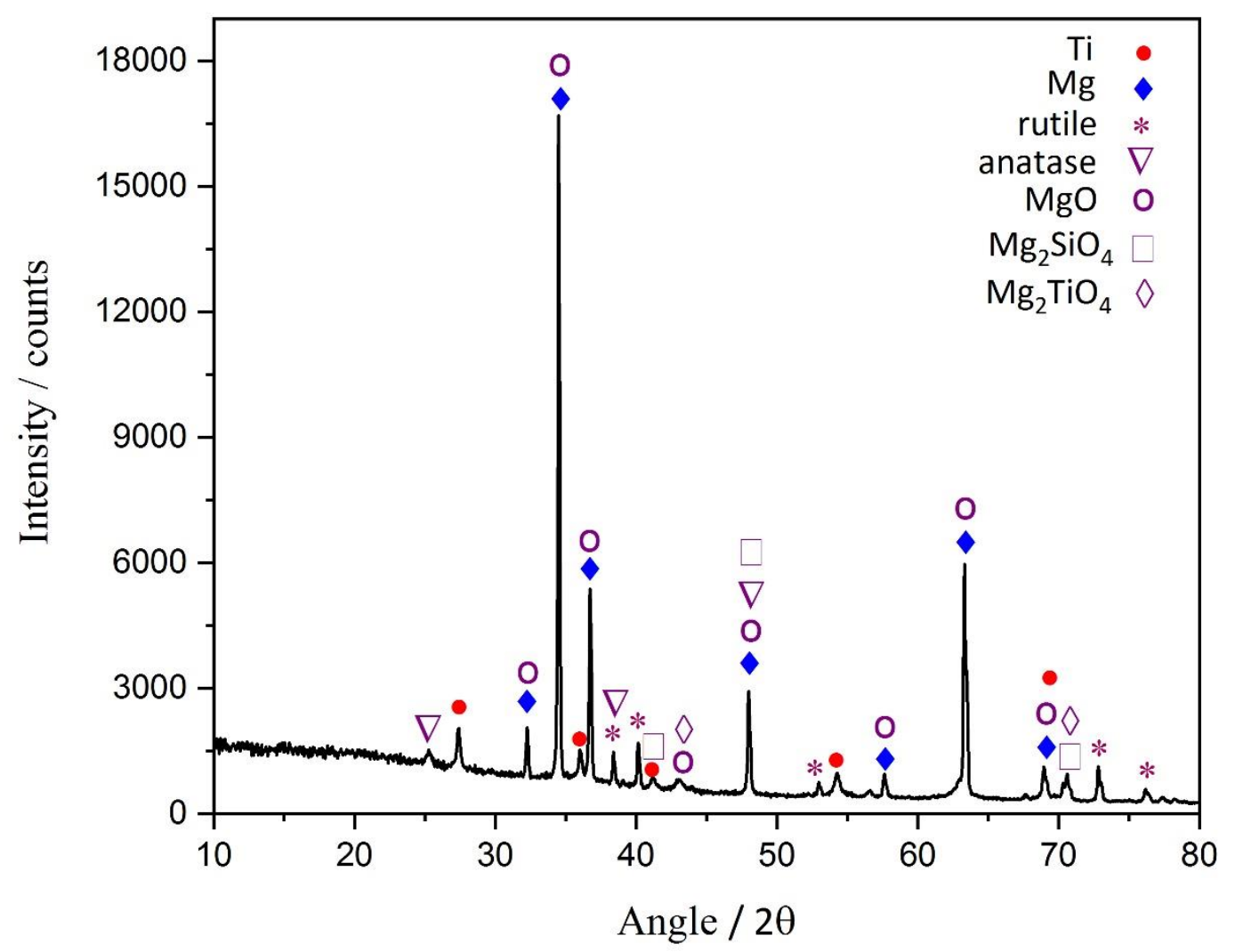

Fig 4 


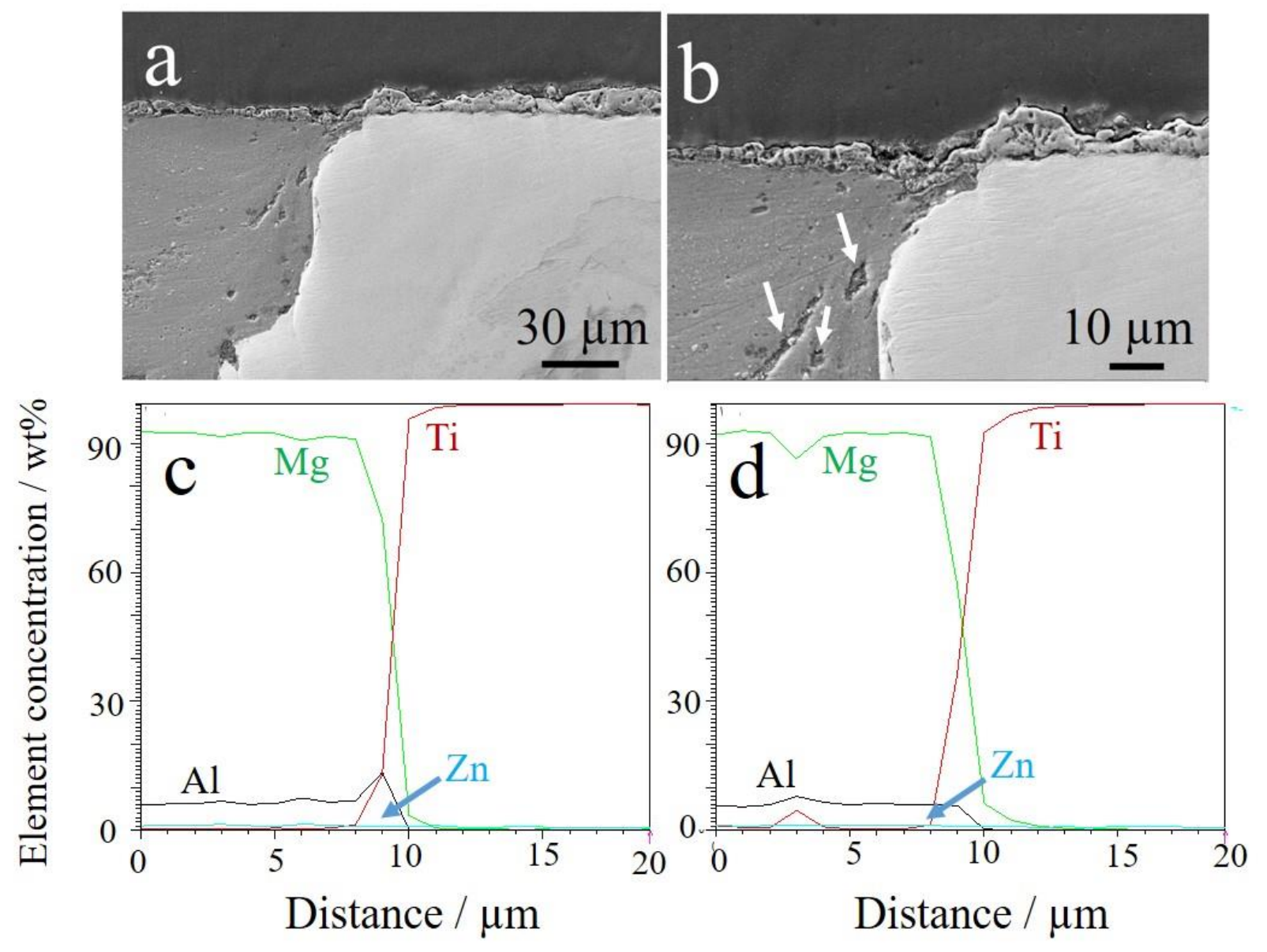

Fig 5 


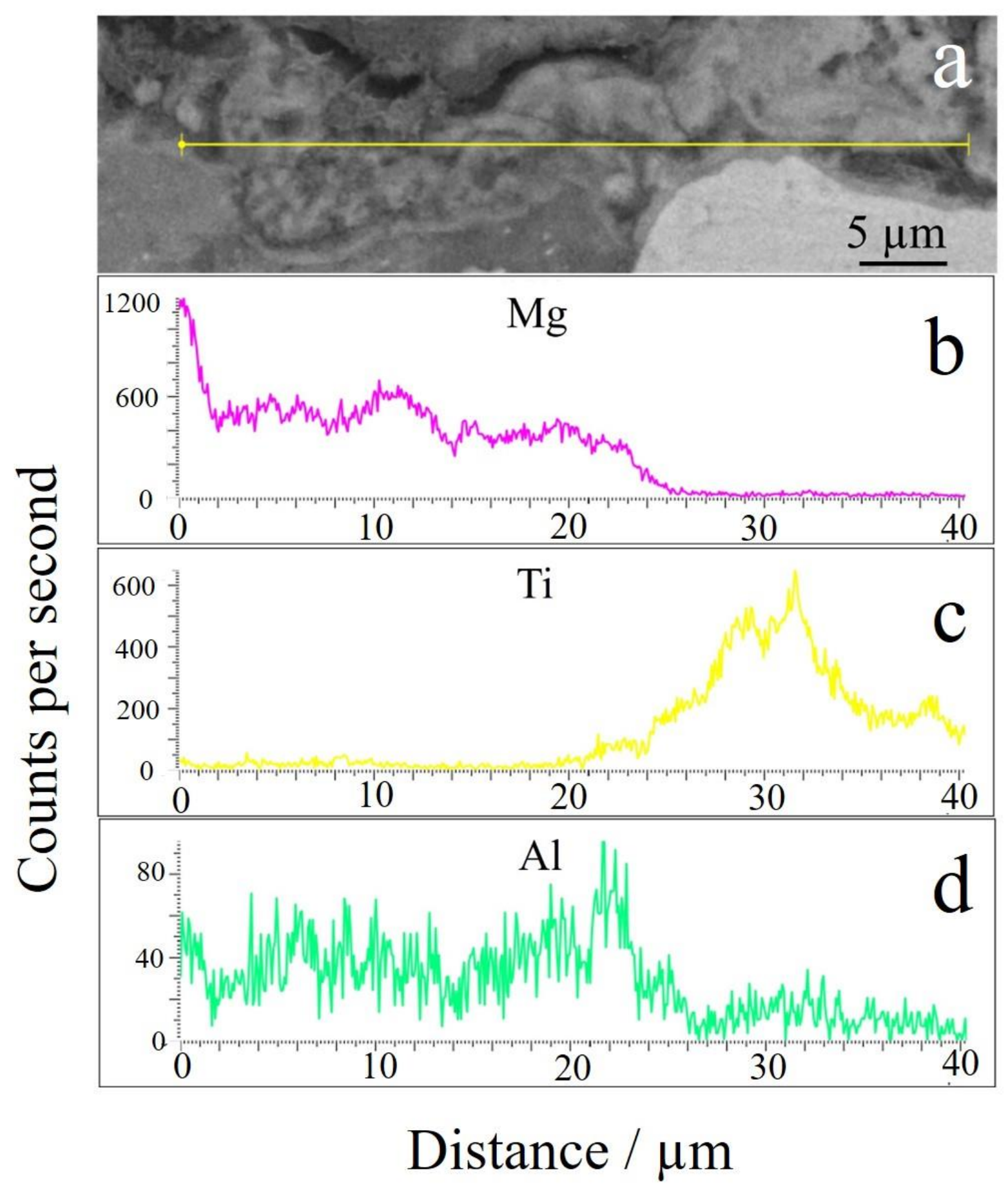

Fig 6 


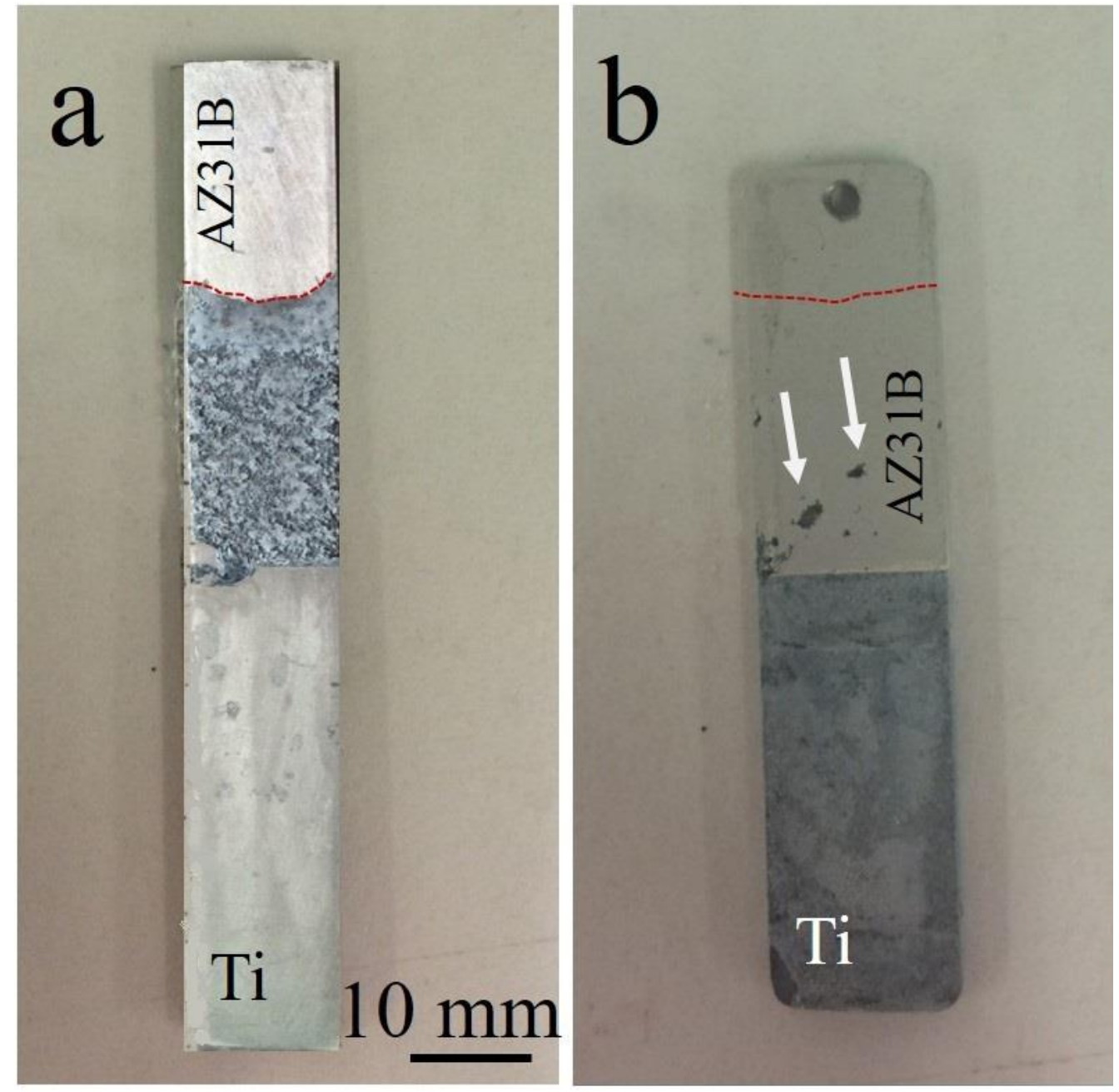

Fig 7 


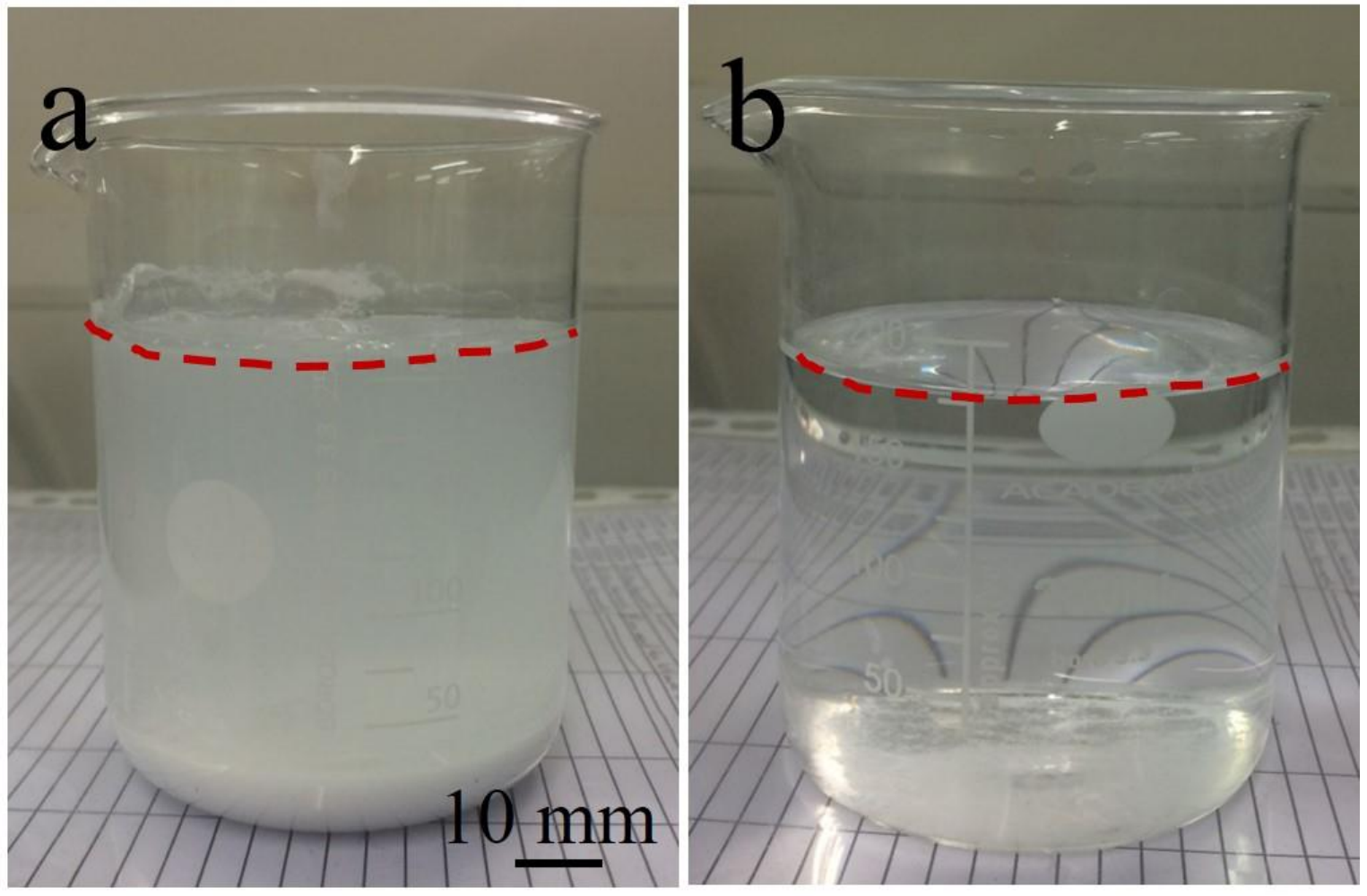

Fig 8

Table 1. Results of EDS analysis.

\begin{tabular}{c|ccccccc}
\hline \multicolumn{1}{c|}{ Regions (at\%) } & $\mathrm{Na}$ & $\mathrm{Si}$ & $\mathrm{O}$ & $\mathrm{K}$ & $\mathrm{F}$ & $\mathrm{Mg}$ & $\mathrm{Ti}$ \\
\hline coating on AZ31B & 0.7 & 8.9 & 61.3 & 0.3 & 2.7 & 26.1 & - \\
coating on titanium & 0.7 & 14.5 & 72.9 & 0.5 & 1.6 & - & 9.8
\end{tabular}

